\title{
Histopathological response of resistance induced by salicylic acid during brinjal (Solanum melongena L.) - Verticillium dahliae interaction
}

\author{
H M Mahesh, M S Sharada* \\ Department of Studies in Botany, Manasagangotri, Mysore, Karnataka, India
}

ARTICLE INFO

Article history:

Received on: November 13, 2017

Accepted on: December 27, 2017

Available online: February 17, 2018

\section{Key words:}

Eggplant,

Host-pathogen interaction,

Hypersensitive reaction,

Papillae,

Salicylic acid,

Verticillium Wilt.

\begin{abstract}
Verticillium dahliae Klebhan is a soil-borne vascular pathogen, found in temperate regions all over the world. Salicylic acid (SA) treated and untreated seedlings of brinjal were histologically investigated for their infection and defense response to wilt causing and defoliating strain of $V$. dahliae Kleb. SA plays an important role in signaling and the activation of various plant defense responses to pathogen attack. SA has been used to control the disease (Verticillium wilt) with the different concentrations, namely, 0.25, 0.5, 0.75, and $1.0 \mathrm{mM}$. Histopathological studies have been conducted at different time gap studies (namely, 0, 3, 6, 12, 24, 48, 72, and $96 \mathrm{~h}$ ), whereas the SA-primed seedlings acquired resistance by forming papillae, hypersensitive reaction, cell wall thickening, etc. In the susceptible seedlings, $V$. dahliae colonizes through the primary roots, the infection process increased at $24 \mathrm{~h}$ after inoculation, and ramification increases at $72 \mathrm{~h}$ which finally leads to death. However, the infection process showed a significant difference between susceptible and SA-treated seedlings of eggplant. The $V$. dahliae showed slow infection process in SA-treated brinjal seedlings along with defense structures.
\end{abstract}

\section{INTRODUCTION}

Verticillium wilt caused by Verticillium dahliae Klebahn in brinjal (Solanum melongena L.) is a destructive disease [1]. The pathogen causes Verticillium wilt to more than 200 plant species including potatoes, strawberry, alfalfa, oilseed crops, and several tree spp. such as maple and olive [2-6]. Verticillium wilt disease can be severe case, which causes a disease incidence up to 70\% [7]. The microsclerotia are viable for many years in soil which help them to cause the disease [8]. Verticillium spp. has been reported to produce cell wall degrading enzymes and phytotoxins that help to induce disease in plants [9]. Pathogen is naturally found in the soil, as they infect host through the roots and invade the vascular tissue and block the food and water supply leading to wilt. In Verticillium-infected hosts, several phases can be distinguished in the life cycle of $V$. dahliae as they infect the root system, colonization of vascular bundle, and finally, symptoms developed such as necrosis, wilting, and yellowing of leaves $[2,10,11]$. Following penetration into the root vascular system, pathogen colonization of above-ground vascular tissues of trees can be very rapid, finally reaching leaf petioles [12].

\section{*Corresponding author}

Dr. M. S. Sharada,

Department of Studies in Botany,

Manasagangotri, Mysore - 570006 ,

Karnataka, India.

Email: Mahy.hsn666@gmail.com
Brinjal is one of the important vegetable crops grown extensively in the tropical and subtropical belts of the world [13]. The infected eggplants by the $V$. dahliae cause yellow and brown leaf spots, discoloration of vascular bundle, loss of yield, reduction growth, and fruit quality and lead to the death of the plant [14]. The disease has ability to destroy an entire crop in the infected areas with $V$. dahliae [15]. Resistance acquired by plants on treatment with the various inducing agents is generally expressed as a hypersensitive reaction (HR) of the penetrated cells followed by other histological changes such as cell wall lignification, callose deposition, and cell wall thickening due to deposition of compounds including phenolic substances and hydrogen peroxide, thereby barricading the spread of the pathogen [16].

Salicylic acid (SA) is a derivative of phenol, distributed in a wide range of plants. It is directly involved in plant growth, flower induction, thermogenesis, and uptake of ions [17], and it is also involved in the plant defense-related actions against various pathogen attacks. Systemic acquired resistance (SAR) is dependent on SA production and the expression of NPR1 (non-expressor of pathogenesis-related [PR] protein). This NPR1 protein found downstream of SA and triggers the expression of several PR genes [18]. SAR is a nonspecific, systemic, and long-lasting defense mechanism that enhances resistance to infections by pathogens [19].

The aim of the present investigation was to find the different stages of infection process or life cycle of $V$. dahlaie using SA to acquire resistance in eggplant. 


\section{MATERIALS AND METHODS}

\subsection{Collection of Samples}

Seeds of brinjal cultivar (cv.) Local M5 susceptible (unpublished data) to Verticillium wilt were obtained from Srirangapatna, Mandya, Karnataka, India, and used throughout the study.

\subsection{Isolation of Pathogen $V$. dahliae}

Brinjal plants displaying typical symptoms of Verticillium wilt (root and stem) were collected from brinjal growing regions of Karnataka, India. The infected plant material was surface sterilized with $2 \%$ sodium hypochlorite solution and repeatedly washed with sterile distilled water (SDW). Moisture was absorbed on sterile filter paper and the infected plant materials were placed on potato dextrose agar (PDA) medium supplemented with chloramphenicol $(100 \mathrm{mg} / \mathrm{L})$. All plates were incubated at $25^{\circ} \mathrm{C} \pm 2{ }^{\circ} \mathrm{C}$ for 7 days, and fungal colonies showing typical symptoms of $V$. dahliae were picked using sterile inoculation needle and subcultured on PDA. The fungal isolate was confirmed based on morphology, conidiophores, conidia, and presence of microsclerotia [20].

\subsection{Preparation of Inoculum}

$V$. dahliae pure cultures grown on PDA (10-15 days) were flooded with $5-10 \mathrm{ml}$ of SDW for each plate and spores were dislodged by shaking or using a sterile brush. The spore suspension was passed through double layer cheesecloth. The concentration of the spore suspension was adjusted to $1 \times 10^{7}$ spores $\mathrm{mL}^{-1}$ using hemocytometer and used as standard inoculum throughout the study [21].

\subsection{Preparation of $S A$}

Aqueous solutions of SA (Sigma-Aldrich) were prepared at different concentrations, namely, $0.25,0.5,0.75$, and $1.0 \mathrm{mM}$. The surface sterilized brinjal seeds were primed with various concentrations of SA by placing 400 seeds in $50 \mathrm{ml}$ for $3 \mathrm{~h}$ in a rotary shaker at $25^{\circ} \mathrm{C} \pm 2{ }^{\circ} \mathrm{C}$. The SA primed seeds were aseptically air-dried and used throughout the study. Seeds treated with SDW served as control.

\subsection{HR}

HR was studied in the test seedlings as described by Kumudini et al. [22]. The inoculated seedlings of eggplants (different concentrations of SA and control) were observed for the external appearance of necrotic spots or streaks on the stem regions of the test seedlings at different time intervals $(0,3,6,12,24,36,48$, and $72 \mathrm{~h})$ after inoculation. The initial time of appearance of HR and the number of seedlings showing the necrotic spots during the experimental period were recorded, and the percent HR cells were calculated. The experiment consisted of three replicates of 20 seedlings each and repeated thrice.

\subsection{Maceration Techniques}

Maceration technique was carried out by Sharada et al. [23]. The seedlings treated with different concentrations of SA and control were macerated in $3 \%(\mathrm{~W} / \mathrm{V})$ sodium hydroxide for $30 \mathrm{~min}$ at $60^{\circ} \mathrm{C}$, thoroughly washed in running water for $30 \mathrm{~min}$ to remove sodium hydroxide. The washed seedlings were transferred to $0.2 \%(\mathrm{~W} / \mathrm{V})$, warm cotton blue, and stained for $2 \mathrm{~h}$. Then, the seedlings were observed under a microscope.

\subsection{Microscopic Observations}

Histological observations were made for the fungal penetration and establishment in the roots of brinjal seedlings using a compound microscope $(10 \times$ and $40 \times)$. The sequential processes of the formation of germ-tube and papillae were observed. The percentage of the cells of roots colonized by the infecting pathogen and the numbers of papillae in brinjal seedlings were counted after inoculation of 30-day-old seedlings. The sequential formation of germ tubes and papillae [23] after treatment with different concentrations of SA along with control (untreated) were observed, counted, and compared.

\section{RESULT}

The different events took place during the pathogenesis in both SA treated and untreated in brinjal with different degrees of resistance to Verticillium wilt disease is explained in the histological method. Eggplant and susceptible host inoculated with pathogen were infected; symptoms of leaf chlorosis and necrosis were first observed. Infected plants were usually stunted, leaf wilting, curling, and defoliation developed along with vascular discoloration.

The disease symptoms appeared first on the lower side of the shoot system. The chlorosis and necrosis were observed in the leaflets. There was the presence of more germ tubes of pathogen in the untreated seedlings but found resistant structures such as HR, papillae, and cell wall thickenings in SA-treated seedlings.

\subsection{HR}

HR was observed in the form of brown necrotic spots. A time course study on HR was conducted to analyze the effect of SA on the expression of defense reactions at the cellular level. However, the intensity and the number of seedlings showing HR were more in SA-treated challengeinoculated seedlings when compared to control seedlings. In Figure 1, HR was observed as early at 6 h.a.i and reached maximum at 72 h.a.i. in SA treated, while in control seedlings, HR was noticed at 24 h.a.i and reached maximum at 72 h.a.i. The plants showed around the 2.5fold increase in the HR in the cells when compared to control.

\subsection{In the Susceptible Seedlings}

Root penetration of the pathogen starts into the vascular system after inoculation. However, invading mycelia were seen inside at the epidermal, cortical, and vascular tissues of the inoculated seedlings. The spores adhere on the tissues of the host which further leads to germ tube formation resulting in mycelial development confirming the infection process towards the vascular region [Figure $2 \mathrm{a}$ to $2 \mathrm{~d}$ ]. Finally complete ramification can be seen in most of the host cells [Figure 2e]. The germinated spores give rise to mycelia which are confirmed based on morphology, conidiophores, conidia, and phialides [Figure 2e]. Then, it started its colonization in the xylem and ramification [Figure $2 \mathrm{~d}$ and e]. The germ tubes were observed at $6 \mathrm{~h}$ after inoculation and reached a maximum at $72 \mathrm{~h}$ after inoculation. In Figure 3, it was noted that the plants showed more than 3-fold decrease in the germ tube germination when compared to control

\subsection{In SA-treated Seedlings}

In the SA-treated seedlings, the structural and histological responses to penetrations are visible in three areas such as (i) papillae - it is a domelike structure or conical growth protruded from the epidermal wall under the appressorium. It often forms near the junction of two cells. The prevention of infection can be seen by the formation of papillae on the cell wall of host [Figure 4a]. (ii) the disk- it is a circular or elliptical area of altered epidermal wall extended outward from the point of attempted penetration; and (iii) altered lateral wall - the wall passed 
under the disk that was slightly thickened [Figure 4c], and the cell wall apposition layers were common in the roots of SA-treated seedlings. The wall appositions created in opposite sides of the attempted penetration sites were apparently prevented the entry of hyphae into the exodermal cell protoplast [Figure 4b]. The papillae is found in the center of the cell along with cell wall thickenings [Figure 4d].

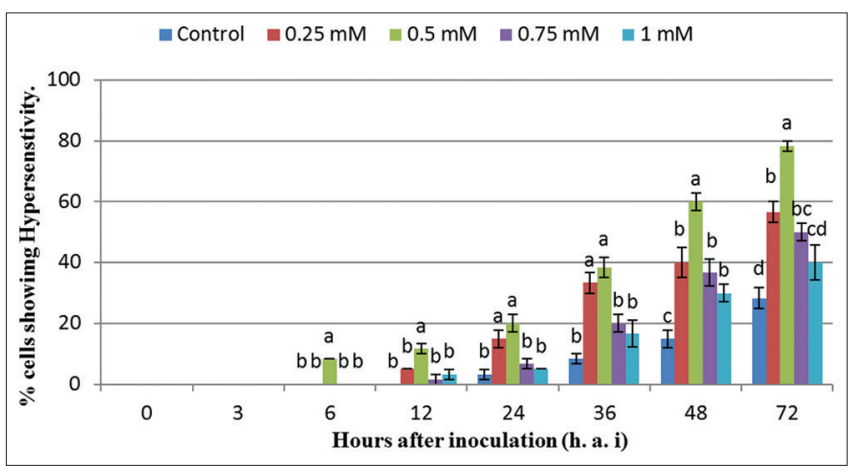

Figure 1: Effect salicylic acid on hypersensitive reaction (HR) in brinjal seedlings after infection with Verticillium dahliae. Time: Course analysis of HR in brinjal seedlings on treatment with salicylic acid against $V$. dahliae.

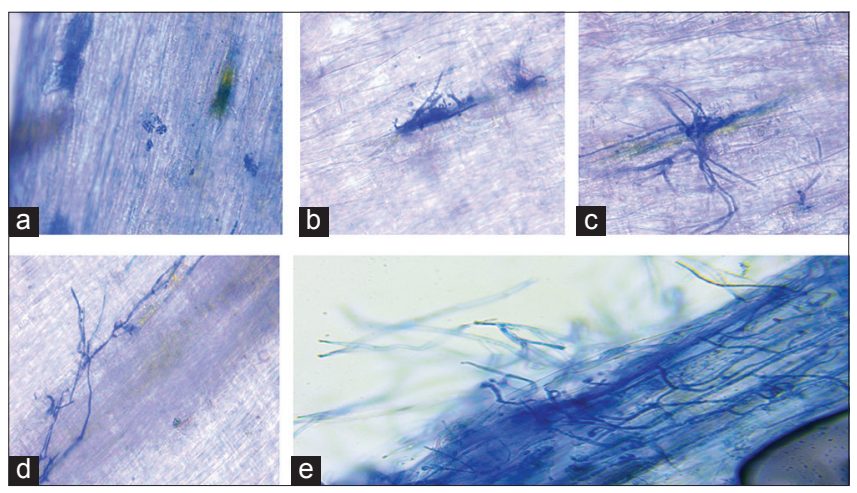

Figure 2: The infectious process in the eggplant seedlings after the inoculation of the pathogen. (a) Spores adhere on the surface of host cells.

(b) The spores started germinating by foaming germ tubes. (c) The germinated spores starts the formation of hyphae. (d) The mycelium started infection toward the vascular region. (e) Complete ramification of the pathogen throughout the host cells.

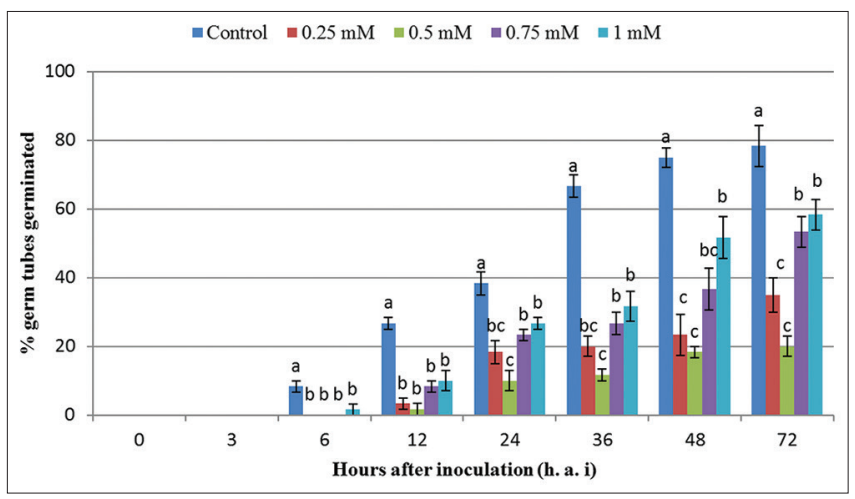

Figure 3: Effect of salicylic acid (SA) on inhibition of germ tube growth of Verticillium dahliae. Time: Course analysis of germ tube germination in brinjal seedlings on treatment with SA against of $V$. dahliae.
The papillae observed $6 \mathrm{~h}$ after inoculation of the pathogen. $0.5 \mathrm{mM}$ SA-treated seedlings offered the presence of more papillae showing resistance followed by $0.25,0.75$, and $1.0 \mathrm{mM}$ concentrations. At the $72 \mathrm{~h}$ after inoculation, in Figure 5, it was noted that the cells showed around the 2.5 -fold increase in the formation of papillae when compared to control.

\section{DISCUSSION}

In the present study, we deal with the differential responses of resistance and infection by primed SA and control seedlings after inoculation with $V$. dahliae. The result supports the hypothesis that papillae formation and HRs function as a resistance mechanism.

Plant reacts irrespective of the stress involved, resulting in activation of several biochemical and physiological changes in the host to withstand the stress involved including, the expression of pathogenesis-related (PR) proteins [24]. Priming of SA induces pathogenesis-related (PR) proteins such as chitinase and $\beta-1,3$ glucanase in eggplant against $V$. dahliae. [25].

The initial infection and colonization of brinjal roots by $V$. dahliae occurred in undifferentiated tissues at the root tip, zone of elongation,
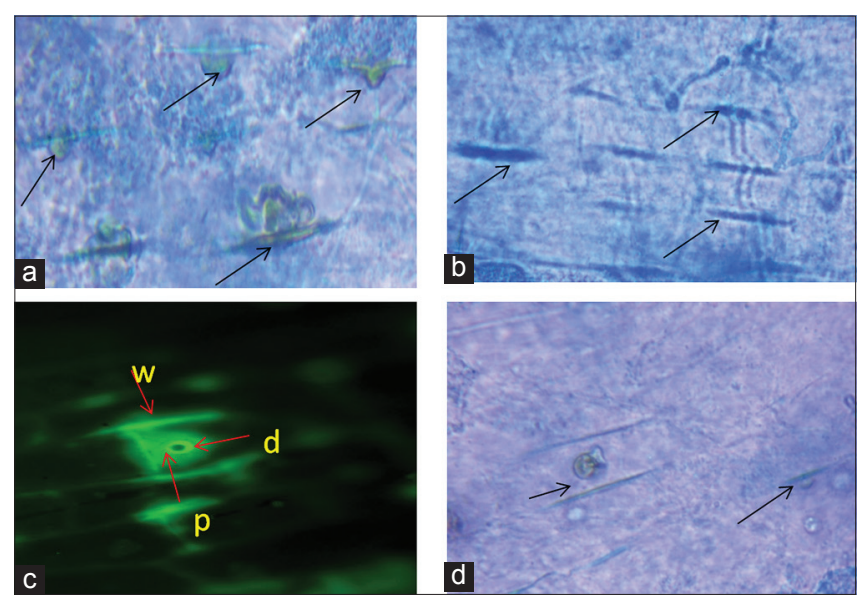

Figure 4: The infectious process in salicylic acid treated seedlings showing resistance structure. (a) Formation of papillae on the cell wall of host. (b)

Formation of cell wall thickenings. (c) Papillae seen during the callose deposition along with desk and wall thickenings. $(0.005 \%$ Aniline blue in $0.15 \mathrm{M}$ dipotassium hydrogen phosphate $(\mathrm{pH} 8.2)$ as stain and mounted under fluorescence microscope). (d) Papillae formed as resistant structure.

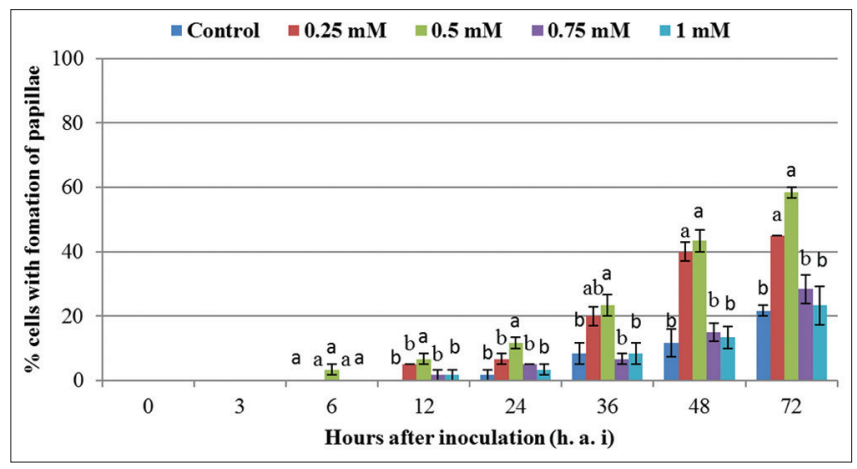

Figure 5: Effect of salicylic acid on the formation of papillae in brinjal seedlings against Verticillium dahliae. Time: Course analysis of formation of papillae in brinjal seedlings on treatment with salicylic acid against $V$. dahliae. 
and even in the trichomes often. The successful infection occurs from the tips of roots and cells of cortex toward the vascular tissues and endodermis surrounding the stele. $V$. dahliae is the primary pathogen infection associated with root deterioration of brinjal. It correlates with the findings of Mueller et al. [26], which is associated with root deterioration of horseradish in Wisconsin. After penetration into the roots, the pathogen invaded the root cortex (both inter- and intracellularly), and the hyphal network reaches the vascular tissue [27]. It was clear observation that the hyphae to be directed toward the vascular tissues and majority of hyphae were concentrated internally growing along the epidermis. Hyphal growth along the epidermis parallel to the stele has also been reported [28]. The pathogen does not cause infection directly to epidermis, cortex, and vasculature; it may enter through trichomes, stomata, damage to the roots, and sometimes injury by the nematodes [29]. Successful invasion by the pathogen will depend on how quickly the fungus finds a direct entry into the vascular system of the root, and this, of course, is readily available through damaged roots during transplantation. Injury caused by nematodes increases the incidence of the disease in egg plants [30]. V. dahliae infects the main roots and remained in the region below the cotyledon node of the plants. [31]. Accelerated flowering has also been linked to a susceptible response to $V$. dahliae in Arabidopsis thaliana [32]. As the disease initiated, the hyphae penetrate all the tissues in the vascular tissues and grow toward the cortex. In the infected root, vessels contain conidia and hyphae that accumulate at the perforation plates [33].

The resistant seedlings upregulated by defense response by showing papillae, cell wall thickenings, and HRs $[16,34]$. The numerous modifications were recorded in root cell walls of both the susceptible and the resistant line, including paramural deposits layers or papillae and cell wall thickenings. Apposition layers were more commonly present in paramural areas of phloem and xylem parenchyma cells in the roots of the resistant line than in the susceptible line. Hong et al. [35] suggested that the structure, physiology, and biochemistry of resistant cotton delayed the infection process compared with susceptible cotton. Raj et al. [16] reported that hypersensitive response which is visually observed as brown necrotic spots or streaks representing rapid and localized cell death is associated with resistance responses in interaction between plants and pathogen.

Studies have also demonstrated that PR proteins are induced in pathological situations in plants, produced through salicylicdependent pathway, and considered as a part of the multiple defense systems of plants [36]. Our results suggested that the histological responses such as HR, papillae, and cell wall thickenings may be the important mechanisms by which SA priming reveals the resistance against Verticillium wilt disease. The pathogen penetrates the roots of brinjal and induced the deposition of lignotubers in the cell walls of the host which also observed in Griffiths [37] of tomato and pea seedlings. Fellows [38] used the word lignotuber in his account of the invasion of wheat roots by Ophiobolus graminis to describe such structures and wall oppositions to explain the protrusion of the host cell wall at the point of fungal penetration; similar structures have been frequently observed in a large number of host/parasite interactions. The reduced disease incidence in tomato by SA and CHT may be a result of cell wall strengthening through deposition of lignin and induction of defense enzymes [39]. We observed papillae formation as a significant response mechanism of the host for containing the fungus at the penetration area. Papillae formation occurs at the interface with the penetration apparatus, and hence, it is energy conservation. The wounding by penetration peg may be alone sufficient to get papillae formation response. These expanding wall appositions may be sufficient barrier to penetrate by the virtue of biochemical-biophysical makeup $[34,40,41]$. The overall results strongly confirm that the SA treatment is an effective method to confer resistance in brinjal against V. dahliae.

\section{CONCLUSION}

From the above preliminary observations, we are encouraged to accept the hypothesis that the SA plays an important role in defense against the Verticillium wilt by histological method. Among the four concentrations, $0.5 \mathrm{mM}$ is said to be preferable concentration for induction of resistance. The host will not allow the pathogen for infection by forming defensive structures to enter through the cell wall. The SA minimizes the rate of germination of germ tube and increases the HR and formation of papillae upon infection.

\section{ACKNOWLEDGMENT}

The authors are thankful to the Department of Studies in Botany, University of Mysore, Mysuru, India, for providing facilities to carry out the research work.

\section{REFERENCES}

1. Kamal M, Saydam C. Verticillium wilt of eggplant in Turkey. Plant Dis Report 1970;54:241-3.

2. Hiemstra JA. A Compendium of Verticillium Wilts in Tree Species. Netherlands: CPRO; 1998. p. 80.

3. Bhat RG, Subbarao KV. Host range specificity in Verticillium dahliae. Phytopathology 1999;89:1218-25.

4. Goud JC, Termorshuizen AJ. Quality of methods to quantify microsclerotia of Verticillium dahliae in soil. Eur J Plant Pathol 2003;109:523-34.

5. Ligoxigakis EK, Vakalounakis DJ, Thanassoulopoulos CC. Weed hosts of Verticillium dahliae in Crete: Susceptibility, symptomatology and significance. Phytoparasitica 2002;30:511-8.

6. Zeise K, Von Tiedemann A. Host specialization among vegetative compatibility groups of Verticillium dahliae in relation to Verticillium longisporum. J Phytopathol 2002;150:112-9.

7. Koike ST, Subbarao KV, Davis RM, Gordon TR, Hubbard JC. Verticillium wilt of cauliflower in California. Plant Dis 1994;78:1116-21.

8. Heale JB, Karapapa VK. The Verticillium threat to Canada's major oilseed crop: Canola. Can J Plant Pathol 1999;21:1-7.

9. Fradin EF, Thomma BP. Physiology and molecular aspects of Verticillium wilt diseases caused by $V$. Dahliae and V. albo-atrum. Mol Plant Pathol 2006;7:71-86.

10. Pegg GF. Life in a black hole-the micro-environment of the vascular pathogen. Trans Br Mycol Soc 1985;85:IN11-20.

11. Pegg GF, Brady BL. Verticillium wilts. Wallingford, Oxon: CABI; 2002.

12. Rijkers AJ, Hiemstra JA, Bollen GJ. Formation of microsclerotia of Verticillium dahliae in petioles of infected ash trees. Neth J Plant Pathol 1992;98:261-4.

13. Thompson CH, Kelly CW. Vegetable Crops. New York: Mc GrawHill Book. Inc; 1957. p. 501.

14. Cirulli M, Ciccarese F, Amenduni M. Progress in the search for Verticillium wilt-resistant eggplant. Phytopathol Mediterr 1990;29:184-90.

15. Marois JJ, Johnston SA, Dunn MT, Papavizas GC. Biological control of Verticillium wilts of eggplant in the field. Plant Dis 1982;66:1166-8.

16. Raj SN, Lavanya SN, Amruthesh KN, Niranjana SR, Reddy MS, Shetty HS. Histo-chemical changes induced by PGPR during induction of resistance in pearl millet against downy mildew disease. 
Biol Control 2012;60:90-102.

17. Vlot Corina D, Dempsey MA, Klessig DF. Salicylic acid, a multifaceted hormone to combat disease. Annu Rev Phytopathol 2009;47:177-206.

18. Glazebrook J. Contrasting mechanisms of defense against biotrophic and necrotrophic pathogens. Annu Rev Phytopathol 2005;43:205-27.

19. Durrant WE, Dong X. Systemic acquired resistance. Annu Rev Phytopathol 2004;42:185-209.

20. Hawksworth DL, Talboys PW. Verticillium albo-atrum. CMI Descriptions of Pathogenic Fungi and Bacteria. Wallingford, UK: CAB International; 1970.

21. Zhou W, Cheng Y, Li Y, Wan Y, Liu Y, Lin X, et al. Novel fungal pelletization-assisted technology for algae harvesting and wastewater treatment. Appl Biochem Biotechnol 2012;167:214-28.

22. Kumudini BS, Vasanthi NS, Shetty HS. Hypersensitive response, cell death and histochemical localisation of hydrogen peroxide in host and non-host seedlings infected with the downy mildew pathogen Sclerospora graminicola. Ann Appl Biol 2001;139:217-25.

23. Sharada MS, Shetty SA, Shetty HS. Infection processes of Sclerospora graminicola on Pennisetum glaucum lines resistant and susceptible to downy mildew. Mycol Res 1995;99:317-22.

24. Murali M, Sudisha J, Amruthesh KN, Ito SI, Shetty HS. Rhizosphere fungus Penicillium chrysogenum promotes growth and induces defence-related genes and downy mildew disease resistance in pearl millet. Plant Biol 2013;15:111-8.

25. Mahesh HM, Murali M, Anup Chandra Pal M, Melvin P, Sharada MS. Salicylic acid seed priming instigates defense mechanism by inducing PR-proteins in Solanum melongena L. Upon infection with Verticillium dahliae Kleb. Plant Physiol Biochem 2017;117:12-23.

26. Mueller JP, Percich JA, Mitchell JE. Root deterioration association with Verticillium wilt of horseradish. Plant Dis 1982;66:410-4.

27. Prieto P, Navarro-Raya C, Valverde-Corredor A, Amyotte SG, Dobinson KF, Mercado-Blanco J, et al. Colonization process of olive tissues by Verticillium dahliae and its in planta interaction with the biocontrol root endophyte pseudomonas fluorescens PICF7. Microb Biotechnol 2009;2:499-511.

28. Gerik JS, Huisman OC. Study of field grown cotton roots infected with Verticillium dahliae using an immunoenzymatic staining technique. Phytopathology 1988;78:1174-8.

29. Bowers JH, Nameth ST, Riedel RM, Rowe RC. Infection and colonization of potato roots by Verticillium dahliae as affected by Pratylenchus penetrans and P. Crenatus. Phytopathology 1996;86:614-21.
30. Mountain WB, McKeen CD. Effects of transplant injury and nematodes on incidence of Verticillium wilt of eggplant. Can J Bot 1965;43:619-24.

31. Zhou L, Hu Q, Johansson A, Dixelius C. Verticillium longisporum and $V$. dahliae: Infection and disease in Brassica napus. Plant Pathol 2006;55:137-44.

32. Veronese P, Narasimhan ML, Stevenson RA, Zhu JK, Weller SC, Subbarao KV, et al. Identification of a locus controlling Verticillium disease symptom response in Arabidopsis thaliana. Plant J 2003;35:574-87.

33. Perry JW, Evert RF. Histopathology of Verticillium dahliae within mature roots of russet burbank potatoes. Can J Bot 1983;61:3405-21.

34. Vance CP, Sherwood RT. Cycloheximide treatments implicate papilla formation in resistance of reed Canarygrass to fungi. Phytopathology 1976;66:498-502.

35. Hong-li X, li K, Zhi-Qiang K, Yu-Ming B, Feng-Xuan Z, Shao-Yan L, et al. Histological observation of cotton infected by Verticillium dahliae. Acta Phytopathol Sin 2014;44:287-94.

36. Kombrink E, Somssich IE. Pathogenesis-related proteins and plant defense. In: Plant Relationships. Heidelberg: Springer Berlin; 1997. p. 107-28.

37. Griffiths DA. The development of lignitubers in roots after infection by Verticillirim dahlia Kleb. Can J Microbiol 1970;17:441-4.

38. Fellows H. Some chemical and morphological phenomena attending infection of the wheat plant by Ophiobolus graminis. J Agric Res 1928;37:647-63.

39. Mandal S, Kar I, Mukherjee AK, Acharya P. Elicitor-induced defense responses in Solanum lycopersicum against Ralstonia solanacearum. Sci World J 2013;2013:561056.

40. Schnathorst WC. Life cycle and epidemiology of Verticillium. In: ME AA CHitor. Fungal Wilt Diseases of Plants. New York: Academic press, Inc; 1981. p. 81-111.

41. Abhayashree MS, Murali M, Thriveni MC, Sindhu GM, Amruthesh KN. Crude oligosaccharides mediated resistance and histo-chemical changes in Capsicum annuum against anthracnose disease caused by Colletotrichum capsici. Plant Biosyst Int J Dealing All Aspects Plant Biol 2017;151:221-33.

\footnotetext{
How to cite this article:

Mahesh HM, Sharada MS. Histopathological response of resistance by

salicylic acid during brinjal (Solanum melongena) - Verticillium dahliae

interaction. J App Biol Biotech. 2018;6(2):61-65.

DOI: $10.7324 / J A B B .2018 .60210$
} 